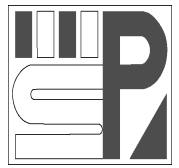

Science Press
Journal of Arid Land

2012, 4(4): 450-456

doi: 10.3724/SP.J.1227.2012.00450

jal.xjegi.com; www.chinasciencejournal.com

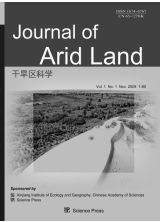

\title{
Influences of landform as a confounding variable on SOM-NDVI association in semiarid Ordos Plateau
}

\author{
YanYun LUO ${ }^{1}$, TingXi LIU ${ }^{1 *}$, XiXi WANG ${ }^{1,2}$, LiMin DUAN ${ }^{1}$ \\ ${ }^{1}$ College of Water Conservancy and Civil Engineering, Inner Mongolia Agricultural University, Hohhot 010018, China; \\ ${ }^{2}$ Hydraulics/Water Resources Laboratory, Department of Civil and Environmental Engineering, Old Dominion University, Norfolk, \\ VA 23529-0241, USA
}

\begin{abstract}
Soil organic matter (SOM) plays an important role in maintaining vegetation cover and thus mitigating land erosion of fragile terrestrial ecosystems such as in the Northern Ordos Plateau of China (NOPC). However, little information is available on whether and how SOM varies spatially as an intrinsic characteristic of landform in NOPC. The objective of this study was to examine the spatial associations of SOM with landform and vegetation cover. The study was conducted in a $23,000-\mathrm{km}^{2}$ area within NOPC because this area has landforms of mobile dunes (MD), flat dunes (FD), grassy sandy land (GSL), flat sandy bedrocks (FSB), and swamps and salt lakes (SW), which are typical landforms in semiarid ecosystems. SOM was determined using a standard laboratory analysis method for $5 \mathrm{~cm}$ topsoil samples collected at 72 locations across the study area. In addition, the $250 \mathrm{~m}$ Multitemporal Moderate Resolution Imaging Spectroradiometer (MODIS) imageries taken in the period from August 2006 to August 2010 were used to extract Normalized Difference Vegetation Index (NDVI) which in turn was used as the surrogate of vegetation cover. Classic and geostatistical methods were used to compare SOM concentration across different landforms. The results indicated that an area with a greater value for NDVI (i.e. better vegetation cover) tended to have a higher SOM concentration regardless of the landform types. However, the association between SOM and NDVI varied from one landform to another. The SW and GSL had a highest SOM concentration, while MD had a lowest concentration. For the study area as a whole and the FD, GSL, and MD, SOM was found to be the sole function of NDVI, whereas, for the FSB, SOM was influenced by several intrinsic variables, namely ground surface altitude, slope, and aspect, as well as NDVI. SOM for the SW landform was found to be a function of NDVI. Furthermore, SOM and NDVI exhibited a consistent spatial pattern of increasing from north to south and from west to east. The highest SOM concentration of $3.5 \%$ occurred along an east-westward belt, which is adjacent to water pathways, in the mid part of the study area.
\end{abstract}

Keywords: MODIS; NDVI; remote sensing; soil organic matter; spatial pattern; topography

Soil organic matter (SOM) is an essential and dynamic variable in terrestrial ecosystems (Zhang et al., 2010). SOM is a product of chemical reaction of photosynthate at one place (Quideau et al., 2001) and subsequently may be redistributed through erosion and deposition processes to alternative places (Six and Jastrow, 2002; Berhe et al., 2007). Because canopy characters of plants (e.g. species composition and density) and the redistribution processes are dependent upon landform characteristics (e.g. topography, surface material composition, and soil surface cover)
(Berhe et al., 2008), soil organic matter usually exhibits spatial variations (Yoo et al., 2006). Landform characteristics influence soil erosion and are also likely to affect SOM spatial distribution. Thus, a good understanding of such variations and their association with landform is very important for protecting fragile terrestrial ecosystems (Sollins et al., 1996; Dall'O' et al., 2001), such as in Northern Ordos Plateau of China (NOPC), and abating impacts of climate change (Dai

\footnotetext{
Received 2012-04-02; accepted 2012-08-06

"Corresponding author: TingXi LIU (E-mail: txliu1966@163.com)
} 
and Huang, 2006). For this reason, a number of researchers (e.g. Lv et al., 2002; Dai and Huang, 2006; Zhou et al., 2008; Martin et al., 2010) examined the spatial pattern of SOM and its controlling variables.

Using field data measured in the Ordos Plateau, Lv et al. (2002) examined the variations of SOM and found that SOM tended to increase from areas with a higher altitude to those with a lower altitude. In the low-lying areas, the SOM content reached its maximum value of about $0.5 \%$. On the other hand, using a total of 886 datasets distributed in different regions of China, Dai and Huang (2006) investigated the relation between SOM concentration, climate, and altitude. They found that the SOM concentration was in general negatively correlated with annual mean temperature, but positively correlated with mean annual precipitation and altitude. Martin et al. (2010) conducted a study in the Indian Himalayan Mountain region and found that the soil organic carbon (SOC), which was used as a surrogate of SOM storage, was significantly higher on hilltops as compared to hillside slopes. The SOC was significantly lower in valleys and piedmonts due to the higher temperature and intensive agriculture which causes higher mineralization of SOC in soils. They concluded that the influence of altitude and climate was more predominant than vegetation type and landform at higher altitudes, but that the influence of landform became more important at lower altitudes. The association between SOM/SOC and altitude from these two latter studies is contradictory to that from Lv et al. (2002). This indicates that altitude probably interacts with other factors (e.g. climate and land management) to influence SOM and/or that the relation between SOM and altitude for one landform may be just opposite to that for another. Information on such relation is needed to develop site-specific protection plans but is poorly documented in existing literature. On the other hand, Zhou et al. (2008) developed a "combined" model, with Normalized Difference Vegetation Index (NDVI) as an important parameter, to estimate the SOM distribution in typical soils in China. The results showed that the incorporation of NDVI significantly improved the spatial precision of estimation and that SOC and NDVI were positively related $\left(R^{2}=0.78\right)$. However, those authors did not examine whether and how the relation for one landform would be different from that for another.

The objective of this study was to examine how landform as a confounding variable influences spatial variations of SOM as a function of vegetation cover in a semiarid environment. That is, we were interested in understanding whether the relation between SOM and NDVI is distinct for different landforms. The study was conducted in a selected area within the semiarid Ordos Plateau. The informative knowledge of SOM spatial variation to be generated in this study is rarely found in existing literature but is very important for land management at a large spatial scale (e.g. watershed) (Peng et al., 2010).

\section{Materials and methods}

\subsection{Study area}

The $23,000-\mathrm{km}^{2}$ study area $\left(39^{\circ} 05^{\prime}-40^{\circ} 53^{\prime} \mathrm{N}\right.$, $106^{\circ} 54^{\prime}-109^{\circ} 14^{\prime} \mathrm{E}$; Fig. 1) is mostly located at NOPC $\left(37^{\circ} 35^{\prime} 24^{\prime \prime}-40^{\circ} 51^{\prime} 00^{\prime \prime} \mathrm{N}, 106^{\circ} 42^{\prime} 40^{\prime \prime}-111^{\circ} 27^{\prime} 40^{\prime \prime} \mathrm{E}\right)$, a region bordered the Loess Plateau to the south and the Yellow River to the north, in the southwest of Inner Mongolia autonomous region of China. The area has an elevation ranging from 956 to $1,772 \mathrm{~m}$ and topographic features of mountains, hills, plains, and rivers. The area has a semiarid climate (DBWCB, 2007), with a mean annual precipitation varying from $200 \mathrm{~mm}$ in the northwest to $260 \mathrm{~mm}$ in the southeast, a mean annual evaporation from 2,600 to $3,300 \mathrm{~mm}$, and an annual mean temperature of around $8.5^{\circ} \mathrm{C}(\mathrm{Li}$ and Zheng, 2002; Hou, 2008; Rao et al., 2011). The vegetation types are true steppe of Stipa bungeana, shrubs of Aretemisia spp., salt meadow and marsh, and desert steppe of Stipa breviflora (Jia, 2000). The study area consists of aeolian sandy, calcic-brown, chestnut, and saline soils (Xu et al., 2009), with 91\% sparse vegetation, $2 \%$ saline swamp, and $7 \%$ steppe (Liu et al., 2005) 


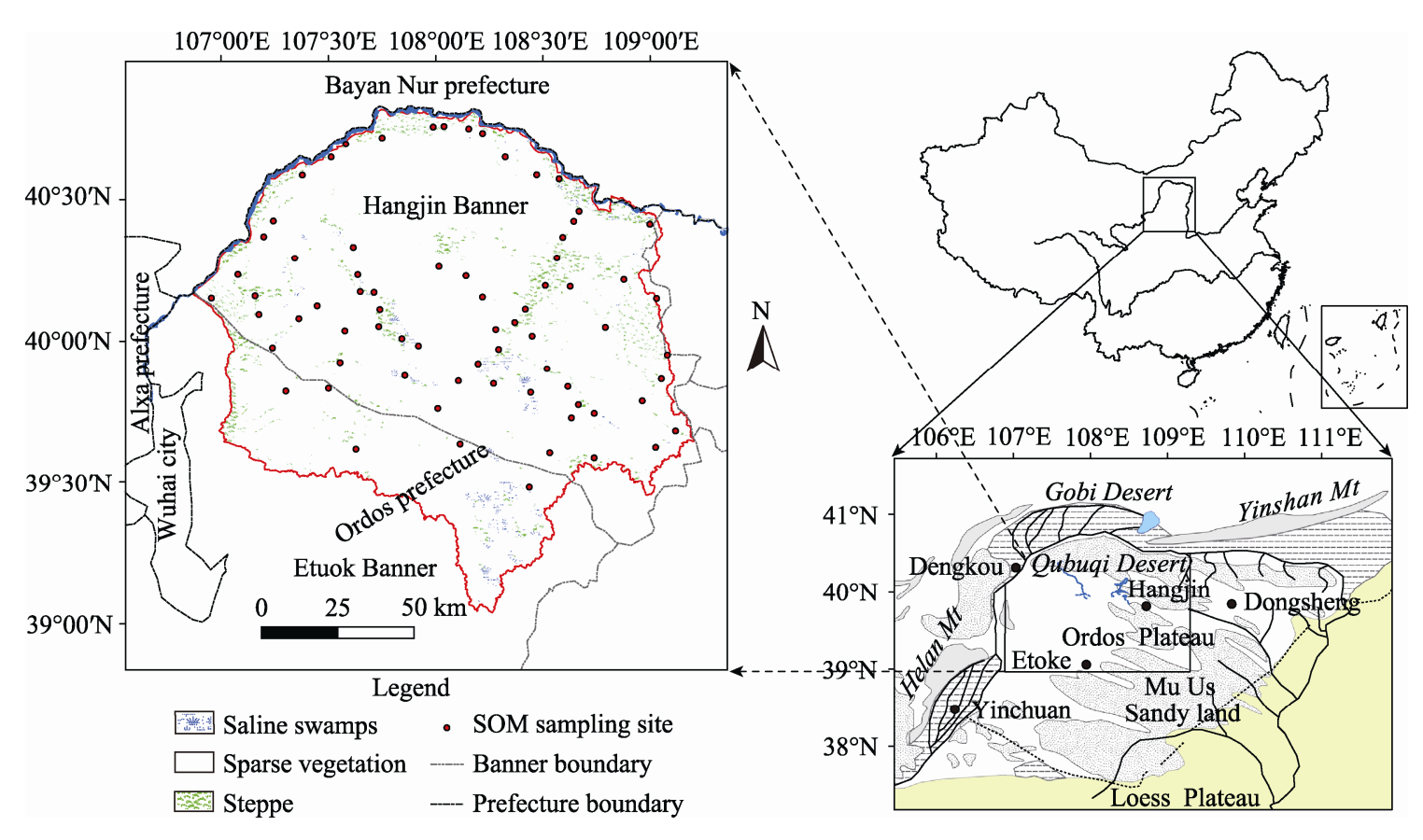

Fig. 1 The study area, land use types and soil organic matter (SOM) sampling sites

\subsection{Soil sampling and analysis}

From 19 to 28 September 2010, soil samples were taken from 5-cm top layer at 72 sites (Fig. 1) across the study area using 50.64-mm diameter and 50-mm height cutting rings with a net volume of $100 \mathrm{~cm}^{3}$. These sites, positioned using a Magellan Explorist 210 GPS System, were least disturbed by human beings. The soil samples were analyzed using the standard Walkley-Black procedure (SSSSC, 1998) to determine values for SOM.

\subsection{Other data}

A 30-m digital elevation model (DEM) and Moderate Resolution Imaging Spectroradiometer (MODIS) images were also used in this study. The DEM was downloaded from the International Scientific \& Technical Data Mirror Site Computer Network Information Center of Chinese Academy of Sciences. MODIS images of the study area for every August from 2006 to 2010 were downloaded from the National Aeronautics and Space Administration (NASA) Earth Observing System (EOS) (ftp://e4ft101.cr.usgs.gov/MOLT/MOD13Q1.005), and subsequently rectified using GPS-positioned field measurements conducted by the authors to have a matching error of one-pixel size (i.e. $30 \mathrm{~m}$ ) or smaller. The MODIS images provide the values of
NDVI at 16-day time intervals. In this study, NDVI in August was used because it can represent best vegetation cover (Stow et al., 2003). Moreover, a map generated from our previous study (Luo et al., 2012) was used to define landform polygons of the study area. The map classifies the study area into the nine landforms (Fig. 2a) of mobile dunes (MD), mobile/semi-mobile dunes (SMD), undulating fixed/semi-fixed dunes (SFD), flat dunes (FD), grassy sandy land (GSL), bedrock (BR), flat sandy bedrock (FSB), valley farmland (VF), and swamp and salt lake (SW). Herein, due to small sizes, SMD and SFD were lumped into MD, FSB was lumped into BR, while VF was lumped into SW.

\subsection{Analysis methods}

The local slope and aspect at a sampling site were derived from the DEM data using ArcGIS 9.2 Spatial Analyst, while the values of NDVI were extracted from the MODIS images using the ENVI Band Math Function and then used to compute the site average for 2006-2010. For each of the nine landforms, an analysis dataset was formulated to include SOM, altitude (ALTI), slope (SLO), aspect (ASP), and NDVI at the sampling sites. NDVI is an extrinsic variable because for a given location it might vary with time, while 

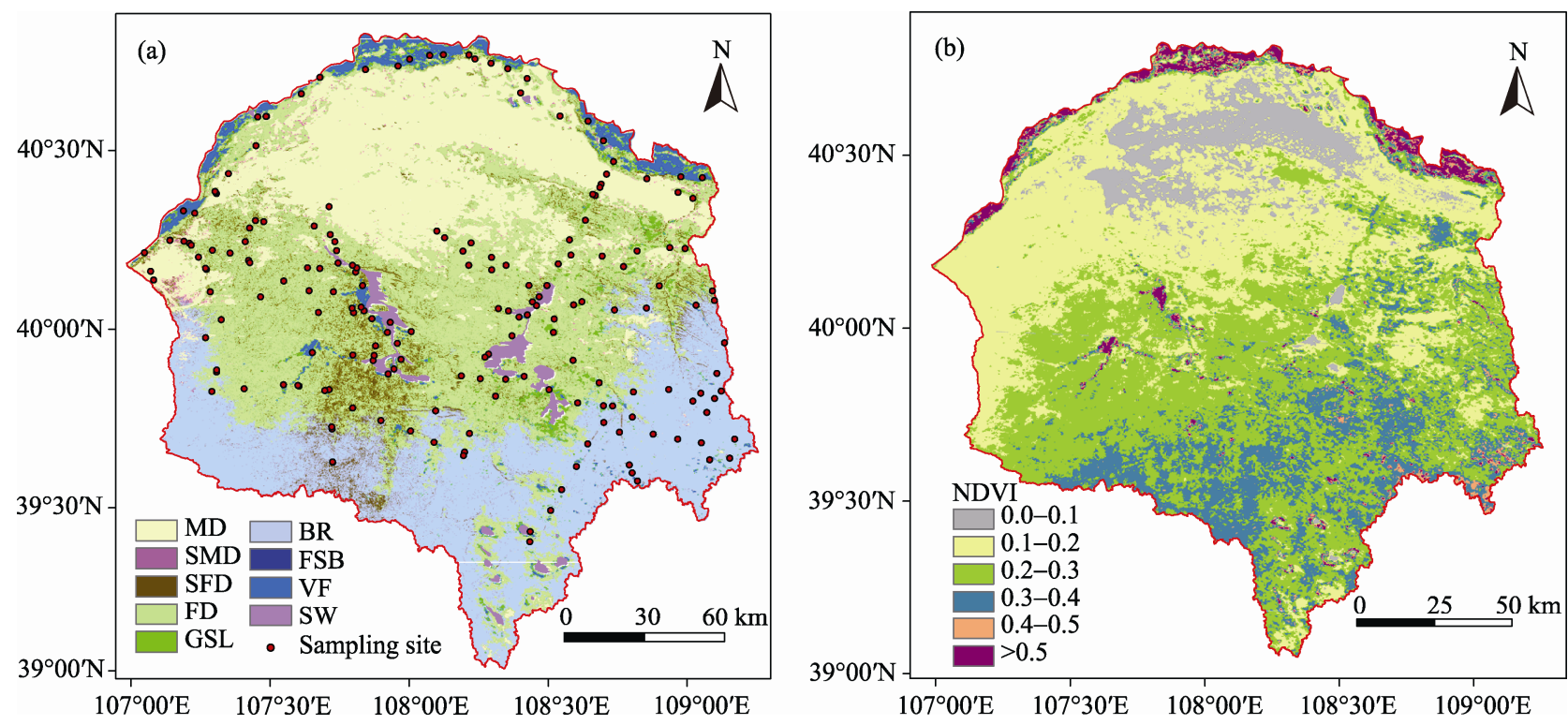

Fig. 2 The landforms (a) generated by Luo et al. (2012) and normalized difference vegetation index (b) developed in this study. MD, mobile dune; SMD, mobile/semi-mobile dune; SFD, undulating fixed/semi-fixed dune; FD, flat dune; GSL, grassy sandy land; BR, bedrock; FSB, flat sandy bedrock; VF, valley farmland; SW, swamp and salt lake.

ALTI, SLO, and ASP are intrinsic parameters because they were not a function of time. Herein, the computed site values for NDVI were used to represent the long-term average vegetation covers at the 72 sampling sites. As a result, nine analysis datasets, each of which was used to analyze SOM spatial variations within its inclusive landform boundary, were formulated. In addition, a pooled dataset was formulated by pooling the nine datasets and used to analyze SOM spatial variations across the landform boundaries (i.e. at the watershed level).

Descriptive statistics (Neter et al., 1996) of the measured 72 values for SOM were computed using Microsoft Excel and SPSS to explore ranges and identify outliers of SOM in the study area. In addition, the pooled dataset was used to generate histograms and Q-Q plots (Neter et al., 1996) to visually determine if the variables follow normal distribution. A natural logarithm transformation was implemented for a variable that is not normally distributed but whose normality is required. In addition, a nonparametric Kruskal-Wallis rank test (Neter et al., 1996) was conducted to verify a null hypothesis that mean SOM is identical for the nine landforms at a significance level of $\alpha=0.05$. The rejection of this null hypothesis would indicate that SOM and landform are statistically associated.
Further, stepwise linear regressions were independently executed in SPSS for the pooled dataset and nine landform-specific datasets to examine which intrinsic and extrinsic variables are significantly associated with SOM. Moreover, an SOM distribution map was generated by interpolating the 72 measured SOM values using the ArcGIS Kriging Interpolation function.

\section{Results and discussion}

\subsection{Descriptive statistics}

A distribution map of the annual average NDVI is shown in Fig. 2b. The NDVI exhibited an increase pattern from north to south and from west to east. This implies that the southeast region of the study area was likely to have a high vegetation cover (NDVI $>0.5$ ). Across the study area, SOM varied between $0.01 \%$ and $3.37 \%$, with a mean of $0.75 \%$ and a standard deviation of $0.74 \%$. The histograms and Q-Q plots (the results are not shown) revealed that SOM is not normally distributed but the other four variables (i.e. NDVI, ALTI, SLO, and ASP) are approximately normal. However, logarithm-transformed SOM was found to be approximately normal and thus used in the stepwise regression analysis. In addition, the KruskalWallis test indicated that SOM varied between different landforms $(P=0.007)$. 


\subsection{Associations between SOM and landform}

For the study area as a whole, SOM was found to be positively associated with NDVI $\left(R^{2}=0.32\right)$ and have no detectable relation with any of the three intrinsic variables (Table 1), indicating that in the study area SOM might mainly be transformed from photosynthate (Six and Jastrow, 2002). Similar associations were also found for the landforms of FD $\left(R^{2}=0.39\right)$, GSL $\left(R^{2}=0.29\right)$, and $\operatorname{MD}\left(R^{2}=0.47\right)$. The relatively high vegetation covers on these three landforms likely contributed a large amount of organic plant residues, some of which were converted into SOM (Wang et al., 2011).

In contrast, SOM in the BR landform was found to be strongly influenced by the intrinsic variables and NDVI $\left(R^{2}=0.86\right)$. The areas with this landform are within floodplains (Fig. 2a) and thus could receive sediments and organic matter from upstream, because sediment transportation by runoff depends on altitude and slope (Wang et al., 2010), which in turn influences SOM in the BR landform. The positive influence of aspect on SOM can be attributed to the fact that decomposition of organic matter on a south-facing slope can be facilitated by receiving more solar radiation energy (Vähäta et al., 1998). For the SW landform, SOM was found to be influenced by NDVI as well $\left(R^{2}=0.84\right.$; Table 1$)$. This is because a large amount of dead plants might be accumulated in the areas with this landform (Jia et al., 2006; Wang et al.,
2007) and higher soil moisture can prompt chemical processes to convert those dead plants into organic matter (Quideau et al., 2001; Yang et al., 2008). In summary, SOM and NDVI were found to be positively associated for each of the nine landforms, but the associations were distinctly different from one landform to another (Fig. 3).

As with NDVI, SOM tended to increase from north to south (Fig. 4). The highest SOM concentration of $3.5 \%$ occurred along an east-westward belt in the mid part of the study area. This belt is adjacent to water pathways, and SOM might be from multiple sources, including deposits and rapid decomposition of dead plants facilitated by high soil moisture. For a given landform, an area with a higher vegetation cover had a greater SOM concentration than an area with lower vegetation cover (Fig. 4 versus Fig. 2b).

\section{Conclusions}

This study examined whether and how the association between SOM and NDVI varied as a function of the nine landforms in a selected region of the semiarid Ordos Plateau. The results revealed that SOM and NDVI consistently increased from north to south and from west to east, and that an area with a greater value for NDVI (i.e. better vegetation cover) tended to have a higher SOM concentration regardless of the landform types. The highest SOM concentration of 3.5\% occurred along an east-westward belt, which is

Table 1 Stepwise linear regression coefficients of natural logarithm-transformed soil organic matter (SOM) on the selected intrinsic and extrinsic variables

\begin{tabular}{lccccc}
\hline & & \multicolumn{3}{c}{ Intrinsic variable } & \multicolumn{2}{c}{ Extrinsic variable } \\
\cline { 3 - 6 } Landform & Intercept & ALTI & SLO & ASP & NDVI \\
\hline Whole area & -2.38 & Excluded & Excluded & Excluded & 6.29 \\
FD (flat dune) & -2.53 & Excluded & Excluded & Excluded & 6.94 \\
BR (bedrock) & -42.45 & 0.02 & 0.20 & 0.01 & 22.22 \\
GSL (grassy sandy land) & -2.08 & Excluded & Excluded & Excluded & 6.54 \\
MD (mobile dune) & -2.41 & Excluded & Excluded & Excluded & 4.78 \\
SW (swamp and salt lake) & -3.07 & Excluded & Excluded & Excluded & 7.35 \\
\hline
\end{tabular}

Note: ${ }^{\text {a }}$ includes flat sandy bedrock (FSB); ${ }^{b}$ includes mobile/semi-mobile dune (SMD) and undulating fixed/semi-fixed dune (SFD); ${ }^{\mathrm{c}}$ includes valley farmland (VF). 

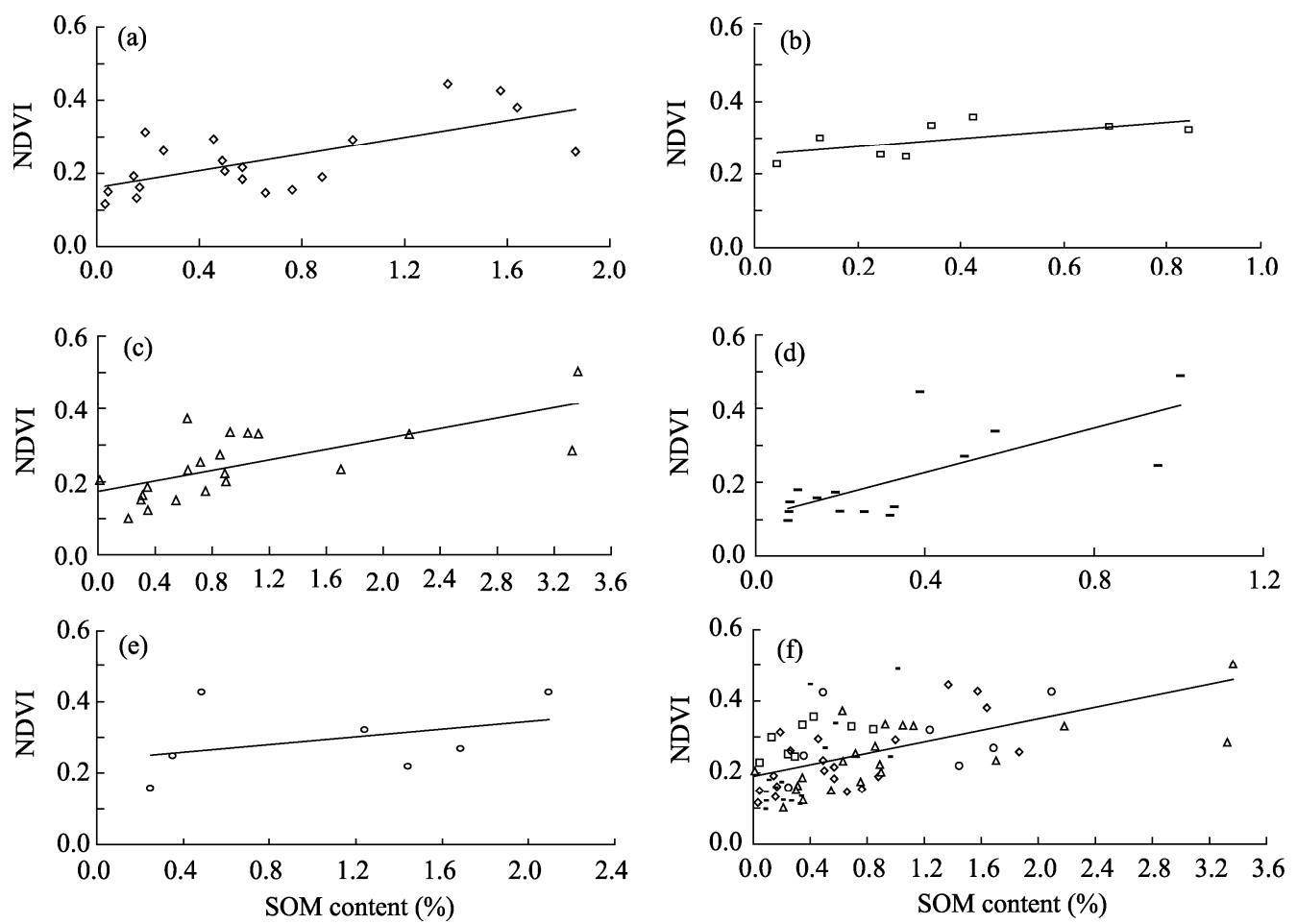

Fig. 3 Plots of normalized difference vegetation index (NDVI) versus soil organic matter (SOM) content for: (a) flat dune landform; (b) bedrock landform; (c) grassy sandy land; (d) mobile dune landform; (e) swamp and salt lake landform; and (f) the whole study area

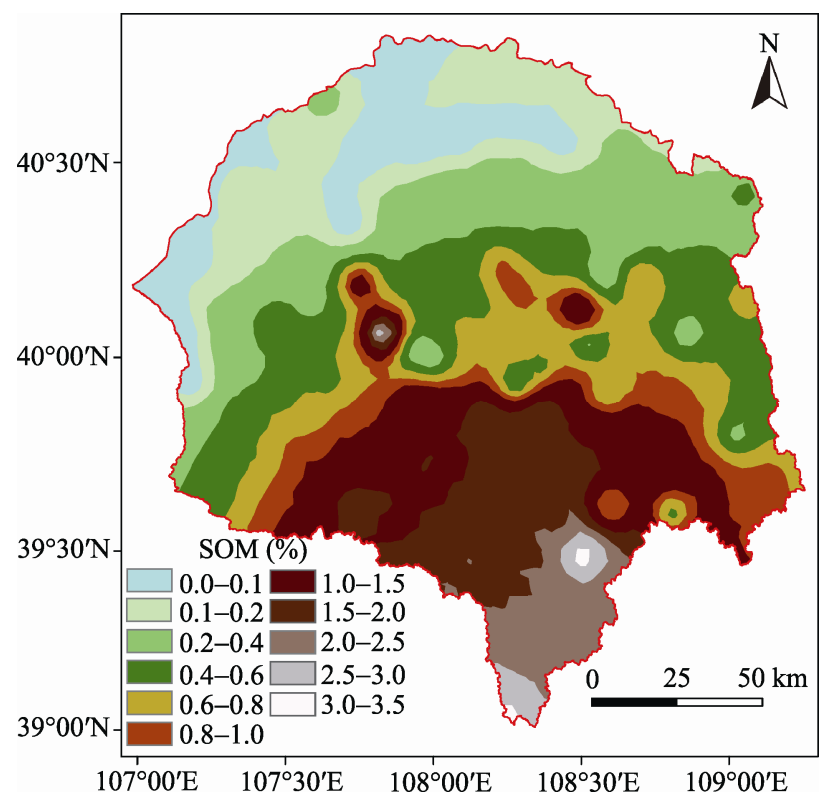

Fig. 4 The spatial distribution of soil organic matter (SOM) content across the study area

\section{References}

Berhe A A, Harden J W, Torn M S, et al. 2008. Linking soil organic matter dynamics and erosion-induced terrestrial carbon sequestration at different landform positions. Journal of Geophysical Research Biogeosciences, 113, G04039, doi:10.1029/2008JG 000751. adjacent to water pathways, in the mid part of the study area. However, the association for one landform was found to be distinctly different from that for another. Thus, in the studied semiarid environment, landform and vegetation cover interactively influenced the spatial variation of SOM, which in turn determined the vegetation population density and growth at a given geographic location.

\section{Acknowledgements}

This research was financially supported by the National Natural Science Foundation of China (51139002 and 51069005), the Inner Mongolia Agricultural University Innovation Team Building Program (NDTD 2010-6), the Inner Mongolia Scientific and Technology Bureau (20090516), and the Chinese Ministry of Science and Technology (2010DFA71460). The authors appreciate the following people for field instrumentation and data collection: Du DAN, HaiYan WANG, JunLiang FENG, RuiLu DUAN, Lei DING, FengLiang WEI, HaiFei XIN, Na LI, GuoFei ZHANG, and Ying CUI.

Dai W H, Huang Y. 2006. Relation of soil organic matter concentration to climate and altitude in zonal soils of China. CATENA, 65(1): 87-94.

Dall'O' M, Kluge W, Bartels F. 2011. FEUWAnet: a multibox water level and lateral exchange model for riperian wetlands. Journal of 
Hydrology, 250: 40-62.

DBWCB (Dalad Banner Water Conservation Bureau). 2007. Introduction of ten largest basins [2011-6-2]. http://www.dlt.gov.cn/ bmwzdh/zfbm/sbj/content/2007-10/17/content_53090.htm.

Hou G C, Zhang M S, Liu F, et al. 2008. Groundwater Exploration in the Ordos Basin. Beijing: Geological Publishing House.

Jia G M. 2006. The effects of vegetation succession and land Management on soil nutrient, activity and structure of microbial community in the Loess Plateau of Northwest China. Ph.D. Dissertation, Lanzhou: Lanzhou University.

Jia J. 2000. Rangeland degradation in Ordos Plateau, its nature and assessment. RALA Report, 200: 87-95.

Li G Q, Zhang Y R. 2002. Characteristics of regional climate change and pattern analysis on Ordos Plateau. Acta Scientiae Circumstantiae, 14(4): 568-576.

Liu L Y, Skidmore E, Hasi E, et al. 2005. Dune sand transport as influenced by wind directions, speed and frequencies in the Ordos Plateau, China. Geomorphology, 67(3-4): 283-297.

Luo Y, Liu T, Wang X, et al. 2012. Landform classification using soil data and remote sensing in northern Ordos Plateau of China. Journal of Geographical Sciences. 22(4): 681-698.

Lv Y Z, Li B Q, Hu K L, et al. 2002. Spatial variability of soil nutrients with different landforms on Erdos Plateau. Soil and Environmental Sciences, 11(1): 32-37.

Martin D, Lal T, Sachdev C B, et al. 2010. Soil organic carbon storage changes with climate change, landform and land use conditions in Garhwal hills of the Indian Himalayan Mountains. Agriculture, Ecosystems \& Environment, 138(1-2): 64-73.

Neter J, Wasserman W, Kutner M H, et al. 1996. Applied Linear Statistical Models. New York: The McGraw-Hill Companies, Inc.

Peng J, Zhang Y Z, Pang X A, et al. 2010. Hyperspectral features of soil organic matter content in South Xinjiang. Arid Land Geography, 55(5): 740-746.

Quideau S A, Chadwick O A, Trumbore S E, et al. 2001. Vegetation control on soil organic matter dynamics. Organic Geochemistry, 32: $247-252$.

Rao W B, Tan H B, Jiang S Y, et al. 2011. Trace element and REE geochemistry of fine- and coarse-grained sands in the Ordos deserts and links with sediments in surrounding areas. Chemie der Erde-Geochemistry, 71(2): 155-170.

Six J, Jastrow J D. 2006. Soil organic matter turnover. In: Lal R.
Encyclopedia of Soil Science. New York: Marcel Dekker.

Sollins P, Homann P, Caldwell B A. 1996. Stabilization and destabilization of soil organic matter: mechanisms and controls. Geoderma, 74: 65-105.

SSSSC (State Soil Survey Service of China). 1998. China Soil. Beijing: Chinese Agricultural Press.

Stow D, Daeschner S, Hope A, et al. 2003. Variability of the seasonally integrated normalized difference vegetation index across the North Slope of Alaska in the 1990s. International Journal of Remote Sensing, 24(5): 1111-1117.

Vähäta A, Søndergaard M, Schlüter L, et al. 1998. Impact of solar radiation on the decomposition of detrital leaves of eelgrass Zostera marina. Marine Ecology Progress Series, 170: 107-117.

Wang H, Guo Z H, Xu X H, et al. 2007. Response of vegetation and soils to desertification of alpine meadow in the upper basin of the Yellow River. China. New Zealand Journal of Agricultural Research, 50(4): 491-501.

Wang X, Shang S, Yang W, et al. 2010. Simulation of land use-soil interactive effects on water and sediment yields at watershed scale. Ecological Engineering, 36(3): 328-344.

Wang Z C, Qian Y B, Zhang H Y, et al. 2011. Spatial distribution of soil physical chemical properties in the region of the northern slopes of Karlike Range in East Tianshan Mountains to Naomaohu Basin. Arid Land Geography, 134(1): 107-114.

Xu D Y, Kang X W, Liu Z L, et al. 2009. Assessment of the relative role of climate change and human activities in sandy desertification of Ordos region, China. Science in China: Series D, 39(4): 516528.

Yang Y C, Hou G C, Zhao Z H, et al. 2008. Formation of mud springs in the Cretaceous Ordos groundwater basin, China and their hydrogeological significance. Geological Bulletin of China, 27(8): 1173- 1177.

Yoo G, Nissen T M, Wander M M. 2006. Use of physical properties to predict the effects of tillage practices on organic matter dynamics in three Illinois soils. Journal of Environmental Quality, 35: 576-583.

Zhang F S, Liu Z X, Geng X Y, et al. 2010. Mapping surface soil organic matter based on multispectral image. 2010 International Conference on Image Analysis and Signal Processing (IASP), April 12-14, 2010, Huaqiao University, Fujian, China.

Zhou T, Shi P J, Luo J Y, et al. 2008. Estimation of soil organic carbon based on remote sensing and process model. Journal of Remote Sensing, 11(1): 127-136. 